\title{
TOTOBUANG
}

Volume 5

Nomor 2, Desember 2017

Halaman 271-283

\section{STRUKTUR SLOT DALAM IKLAN MEDIA LUAR RUANG (Structure of Slot in Outdoor Media Advertisement)}

\author{
Wening Handri Purnami \\ Balai Bahasa Daerah Istimewa Yogyakarta \\ Jalan I Dewa Nyoman Oka 34, Yogyakarta \\ Pos-el: hp.wening@yahoo.co.id
}

(Diterima: 6 November 2017; Direvisi: 27 November 2017; Disetujui: 12 Desember 2017)

\begin{abstract}
Advertisement is an effective tool in messaging. The content of advertisement can be social, political, economic, and so forth for the readers of the lower classes to the upper class. The intended information can be a promotion of a product or an appeal. This study examined the slot structure of outdoor media advertisement. The theory used was structural. This research used qualitative descriptive method and observation technique. Discussion of discourse structures was found in outdoor media advertisement. There are thirteen discourse structures containing name slots, specification slots, attribution slots, and address slots. The thirteen patterns of discourse structure were (1) the address-specification-attribution-address component, (2) the address-specification component, (3) the address-name-attribution component, (4) the address-attribution specification, 5) Component name-specification, (6) component name-specification, (7) address-address component, (8) component-attribution specifications, (9) address-specific components, (10) 11) component names, (12) component specifications, and (13) component attributes.
\end{abstract}

Keywords: advertisement, slot, component

Iklan merupakan sebuah sarana yang dipandang efektif dalam penyampaian pesan. Isi iklan dapat berupa informasi social, politik, ekonomi, dan lain sebagainya bagi pembaca kalangan bawah hingga kalangan atas. Informasi yang dimaksudkan dapat berupa promosi mengenai suatu produk atau imbauan. Penelitian ini mengkaji struktur slot pada iklan media luar ruang. Teori yang digunakan adalah struktural. Penelitian ini menggunakan metode deskriptif kualitatif dan teknik observasi. Hasil pembahasan terkait struktur wacana ditemukan dalam iklan media luar ruang. Terdapat tiga belas struktur wacana yang berisi slot nama, slot spesifikasi, slot atribusi, dan slot alamat. Ketiga belas pola struktur wacana tersebut adalah (1) berkomponen nama-spesifikasi-atribusi-alamat, (2) berkomponen nama-spesifikasi-alamat, (3) berkomponen nama-atribusi-alamat, (4) berkomponen spesifikasi-atribusi-alamat, (5) berkomponen spesifikasi-nama-atribusi, (6) berkomponen nama-spesifikasi, (7) berkomponen nama-alamat, (8) berkomponen spesifikasi-atribusi, (9) berkomponen spesifikasi-alamat, (10) berkomponen atribusi-nama, (11) berkomponen nama, (12) berkomponen spesifikasi, dan (13) berkomponen atribusi.

Kata-kata kunci: iklan, slot, berkomponen

\section{PENDAHULUAN}

Iklan merupakan sebuah sarana yang dipandang efektif dalam penyampaian pesan. Iklan dinilai memiliki kekuatan yang ampuh untuk dapat memengaruhi pembaca atau khalayak agar tertarik atau melakukan apa yang dimaksudkan dalam iklan. Isi iklan dapat berupa informasi sosial, politik, ekonomi, dan lain sebagainya mulai dari tingkat pembaca kalangan bawah hingga pembaca kalangan atas. Informasi yang dimaksudkan dapat berupa promosi mengenai suatu produk atau imbauan. Saat ini, penggunaan bahasa pada papan iklan media luar ruang variatif. Media luar ruang adalah sarana komunikasi yang menggunakan alat tertentu yang diletakkan di luar ruang atau di luar gedung (Pusat Pembinaan, Badan Pengembangan dan Pembinaan Bahasa, 2016). Iklan media luar ruang memberikan dampak lebih karena sangat efektif dan efisien dalam mengomunikasikan 
pesan iklan pada masyarakat yang beraneka ragam seperti contoh berikut ini.

\section{VICTORY \\ MOTOR YOGYAKARTA}

\author{
PENJUALAN GROSIR DAN ECERAN \\ GENUINE PARTS \\ SPARE PARTS; \\ RACING PARTS; \\ CUSTOM/MODIFICATION
}

\section{your motorcycle's solution}

Jl. Brigjen Katamso no. 82 Yogyakarta 55121, (0274) 378402

Contoh iklan di atas berupa iklan jual beli motor. Wacana iklan tersebut tersusun dari beberapa slot. Slot nama (Victory Motor Yogyakarta), slot spesifikasi (Penjualan grosir dan eceran: genuine parts, spare parts; racing parts; custom/modification), slot atribusi (your motorcycle's solution), dan slot alamat (Jl. Brigjen Katamso no. 82 Yogyakarta 55121, (0274) 378402) memiliki fungsi yang berbeda. Slot-slot pada iklan media luar ruang variatif menarik untuk diteliti.

Berdasarkan uraian dalam latar belakang, permasalahan yang akan dibahas dalam penelitian ini seperti berikut.

(1) Bagaimanakah struktur slot dalam iklan media luar ruang?

(2) Apa sajakah fungsi slot-slot dalam iklan media luar ruang?

Penelitian ini bertujuan mencapai hasil sebagai berikut.

(1) Mendeskripsikan struktur slot pada iklan media luar ruang.

(2) Mendeskripsikan fungsi dalam iklan media luar ruang.

Penelitian ini diharapkan dapat bermanfaat baik secara teoritis maupun praktis. Manfaat teoritis ialah menambah pemahaman penggunaan bahasa khususnya pada iklan media luar ruang. Adapun manfaat praktis ialah menambah wawasan bagi para peneliti dan pemerhati bahasa dalam mengkaji penggunaan bahasa iklan media luar ruang. Selain itu, hasil penelitian ini dapat dijadikan bahan untuk menentukan kebijakan terkait dengan kegiatan pembinaan kebahasaan.

Beberapa makalah atau buku hasil laporan penelitian yang relevan dengan penelitian seperti berikut.

(1) Penelitian Pemakaian Bahasa dalam Iklan Berita dan Papan Nama Reklame oleh Zaenal, dkk. (1992) . Penelitian ini mendeskripsikan tentang penggunaan bahasa dalam iklan perniagaan, yang menawarkan barang dagangan dan jasa dan dalam papan reklame, yang meliputi bentuk bahasa iklan perniagaan, penyampaian/pesan bahasa iklan perniagaan, dan kesalahan-kesalahan bahasa iklan perniagaan.

(2) Penelitian berjudul Kajian Wacana Iklan Baris Tentang Properti di Media Massa Cetak oleh Indiyastini (2014). Kajian terhadap wacana iklan baris menghasilkan dua macam struktur bagian, yaitu (1) awal-isi-penutup dan (2) isi-penutup. Pada identifikasi terhadap pemakaian bahasanya, ditemukan adanya penggunaan aneka bentuk singkatan, akronim, kalimat. Berdasarkan pendekatan pragmatic, diketahui adanya penggunaan tuturan tidak langsung yang dimaksudkan untuk mempengaruhi pembaca supaya tertarik pada hal yang ditawarkan.

(3) Buku Penggunaan Bahasa Indonesia pada Media Luar Ruang di DIY oleh Riani, dkk. (2016). Hasil pemantauan dan analisis terhadap penggunaan bahasa pada media luar ruang di Provinsi DIY menunjukkan bahwa masih banyak tulisan yang tidak sesuai dengan kaidah penulisan bahasa Indonesia. Ketidaksesuaian kaidah penggunaan bahasa Indonesia pada media luar ruang tersebut terjadi pada tata ejaan, pola frasa, dan konstruksi kalimat. 
(4) Makalah berjudul "Bahasa Jawa dalam Usaha Jasa Boga di Kota Yogyakarta" oleh Setiyanto (2016). Makalah ini memaparkan struktur wacana nama jasa boga berbahasa Jawa berdasarkan pengisi slot-slotnya. Slot-slot struktur wacana berupa spesifikasi, atribusi, dan alamat. Berdasarkan sifat satuan pengisi slot, bahasa Jawa yang digunakan dalam wacana nama jasa boga dapat dibagi dalam tiga tataran, yaitu klausa, frasa, dan kata.

(5) Buku pedoman Pedoman Pemantauan Penggunaan Bahasa di Media Luar Ruang (2016) oleh Pusat Pembinaan, Badan Pengembangan dan Pembinaan Bahasa. Buku ini mengevaluasi dan mengendalikan penggunaan bahasa yang digunakan di media luar ruang di masyarakat. Hasil evaluasi dan pengendalian itu kemudian digunakan untuk bahan masukan dalam pengambilan kebijakan terkait dengan penggunaan bahasa Indonesia pada masyarakat.

(6) Makalah berjudul "Bahasa Jawa dalam Usaha Jasa Boga di Kota Yogyakarta" oleh Setiyanto (2016). Makalah ini memaparkan struktur wacana nama jasa boga berbahasa Jawa berdasarkan pengisi slot-slotnya. Slot-slot struktur wacana berupa spesifikasi, atribusi, dan alamat. Berdasarkan sifat satuan pengisi slot, bahasa Jawa yang digunakan dalam wacana nama jasa boga dapat dibagi dalam tiga tataran, yaitu klausa, frasa, dan kata.

Berdasarkan beberapa hasil penelitian di atas,penelitian yang membahas lebih mendalam masalah iklan media luar ruang dengan aspek struktur slot belum pernah dikaji. Oleh karena itu, aspek-aspek tersebut menarik untuk diteliti.

\section{LANDASAN TEORI}

Dalam penelitian ini dipaparkan landasan teori berkenaan dengan pengertian struktur, slot, iklan, dan media luar ruang.
Struktur adalah cara sesuatu disusun atau dibangun. Struktur wacana ialah setiap bagian wacana itu memiliki fungsi tersendiri. Bagian awal wacana berfungsi sebagai pembuka wacana, bagian tubuh wacana berfungsi sebagai pemapar isi wacana, dan bagian penutup berfungsi sebagai penanda akhir wacana (Baryadi, 2002:14).

Slot artinya ruang kosong. Iklan adalah pemberitahuan kepada khalayak mengenai barang atau jasa yang dijual, dipasang di media massa (seperti surat kabar dan majalah) atau di tempat umum (KBBI, 2008:521). Secara umum, iklan merupakan suatu bentuk komunikasi nonpersonal yang menyampaikan informasi berbayar sesuai keinginan dari institusi/sponsor tertentu melalui media massa yang bertujuan memengaruhi khalayak agar membeli suatu produk atau jasa (Jaiz, 2014).

Media luar ruang adalah sarana komunikasi yang menggunakan alat tertentu yang diletakkan di luar ruang atau di luar gedung (Pusat Pembinaan, Badan Pengembangan dan Pembinaan Bahasa, 2016). Jadi, iklan media luar ruang adalah iklan yang diletakkan di luar ruang atau di luar gedung. Untuk menganalisis data digunakan teori yang dikemukakan Setiyanto (2012), bahwa sebagai unsur sebuah bangunan setiap bagian wacana itu memerlukan slot-slot sebagai wadah. Dengan kata lain, wacana tersusun dari (a) slot nama, (b) slot spesifikasi, (c) slot atribusi, dan (d) slot alamat. Slot nama untuk membedakan dengan usaha sejenis yang lain. Slot spesifikasi adalah penjelasan mengenai jenis jasa yang ditawarkan. Slot atribusi adalah paparan tambahan untuk lebih menjelaskan hasil produk atau kekhasan layanan. Slot alamat adalah paparan mengenai tempat lokasi usaha yang sering dilengkapi dengan nomor telepon, email, atau laman. 


\section{METODE PENELITIAN}

Penelitian ini menggunakan metode deskriptif kualitatif. Pendekatan deskriptif memiliki tujuan mendeskripsikan objek kajian, yaitu struktur slot iklan. Pendekatan kualitatif digunakan karena data yang dikaji bukan berupa angka-angka, tetapi berupa satuan lingual: kalimat atau kata-kata dalam iklan media luar ruang. Ada tiga tahapan dalam penelitian ini, yaitu tahap pemerolehan data, tahap penganalisisan data, dan tahap penyajian hasil analisis data (Sudaryanto, 2015:6-8) seperti berikut.

Pada tahap pemerolehan data, bentuk iklan media luar ruang yang digunakan sebagai data, seperti baliho, billboard, papan nama usaha, spanduk, dan sebagainya di wilayah DIY. Iklan media luar ruang yang digunakan sebagai data penelitian adalah iklan media luar ruang tersebaran, keterwakilan (bisa berdasar jenis, variabel sosialnya). Data yang telah disimak dan dilakukan teknik rekam visual, yaitu peneliti melakukan perekaman gambar data dengan kamera digital, sehingga diperoleh data berupa foto atau gambar. Metode observasi dengan mengamati iklan-iklan media luar ruang di DIY. Dan melakukan dokumentasi dengan kamera digital. Dari teks pada foto ditranskrip ke dalam ortografis standar.

Data yang berupa foto diklasifikasikan dan dianalisis dengan dasar tertentu. Pengklasifikasian didasarkan pada struktur slot dalam iklan media luar ruang. Metode analisis yang digunakan untuk menjawab permasalahan adalah padan dan agih (Sudaryanto, 2015:37). Untuk menjawab permasalahan struktur slot digunakan metode agih dan teknik sisip dan balik. Data disajikan dengan menggunakan huruf kapital, bukan kapital, tebal, tak tebal, atau miring. Tahap analisis penulisan dengan dimiringkan.

\section{PEMBAHASAN}

Berdasarkan pengamatan pada data iklan di Daerah Istimewa Yogyakarta (Kabupaten Sleman, Kabupaten Bantul,
Kabupaten Kulon Progo, Kabupaten Gunungkidul, dan Kota Yogyakarta), ditemukan tiga belas pola struktur. Pola-pola struktur berisi empat komponen, tiga komponen, dua komponen. Pada komponenkomponen terdapat subpola, yaitu perbedaan urutan komponen. Berikut uraian lebih lanjut mengenai struktut slot pada iklan media luar ruang.

\subsection{Berkomponen Nama-Spesifikasi- Atribusi-Alamat}

Data iklan yang memiliki struktur unsur lengkap nama, spesifikasi, atribusi, dan alamat seperti contoh data (1)-(2) berikut ini.

(1)

' $E$ \& A'

Elektronik dan Alat-Alat Listrik

MEMENUHI KEBUTUHAN ELEKTRONIK KELUARGA ANDA

MENYEDIAKAN:

- LEMARI ES

- SPEAKER AKTIF

- MESIN CUCI

- DVD PLAYER

- TELEVISI

- BLENDER

- ANEKA JENIS KIPAS ANGIN

- SETRIKA

- KOMPOR GAS

- LAMPU

- DESPENSER

- ALAT INSTALASI LISTRIK

- ANTENA

- DLL

\section{MENERIMA PESANAN}

HUB: 082116156470 (WA)

J1. Wates Km 18 Kulon Progo

Yogyakarta

(2)

YYK ADY Trans 
MENYEDIAKAN RENTAL MOBIL DENGAN SOPIR PERJALANAN WISATA JAWA-BALI-LOMBOK

Melayani Reservation:

- HOTEL

- CATERING

- PEMANDU GUIDE

- TIKET OBYEK WISATA

- DOKUMENTASI

\section{Melayani dengan Ramah dan Sepenuh Hati}

Alamat:

Kruwet, Sumberagung, Moyudan, Sleman HP 085879956894/02748214896

J1. Tentara Pelajar No. 14 Yogyakarta

Contoh data (1) dan (2) berupa iklan jenis jasa jual beli dan rental (persewaan). Iklan tersebut memiliki struktur slot lengkap, yaitu slot nama, slot spesifikasi, slot atribusi, dan slot alamat. Contoh data (1) struktur slot nama tuturan ' $E \& A$ '. Bentuk tuturan ' $E \& \mathrm{~A}$ 'disebut sebagai nama untuk membedakan dengan usaha sejenis yang lain. Slot spesifikasi terlihat pada tuturan Elektronik dan Alat-Alat Listrik. Bentuk Elektronik dan Alat-Alat Listrik sebagai spesifikasi untuk menjelaskan jenis usaha yang ditawarkan. Bentuk tuturan memenuhi kebutuhan elektronik keluarga Anda; menyediakan: lemari es, mesin cuci, televisi, speaker aktif, dvd player; blender, aneka jenis kipas angin, setrika, kompor gas; lampu, despenser, alat instalasi listrik, antena, dll. sebagai slot atribusi untuk menjelaskan kekhasan layanan. Struktur pengisi slot alamat berupa tuturanMenerima pesanan hub: 082116156470 (WA); Jl. Wates Km 18 Kulon Progo, Yogyakarta. Bentuk tuturan menerima pesanan hub: 082116156470 (WA); Jl. Wates Km 18 Kulon Progo, Yogyakarta disebut sebagai slot alamat karena dapat memberi petunjuk atau membimbing sampai lokasi usaha.
Contoh data (2) iklan jenis jasa rental atau persewaan tampak struktur pengisi slot nama dapat dilihat pada penggunaan bentuk tuturan $Y Y K$ ADY Trans. Tuturan $Y Y K$ ADY Trans disebut sebagai nama untuk membedakan dengan usaha sejenis yang lain. Struktur pengisi slot spesifikasi terlihat pada tuturan menyediakan rental mobil dengan sopir perjalanan wisata Jawa-BaliLombok; melayani reservation: hotel catering, pemandu wisata (tour guide), Tiket obyek wisata, dokumentasi sebagai spesifikasi untuk menjelaskan jenis usaha yang ditawarkan. Bentuk melayani dengan ramah dan sepenuh hati sebagai atribusi untuk menjelaskan kekhasan layanan. Struktur pengisi slot alamat terlihat pada Alamat: Kruwet, Sumberagung, Moyudan, Sleman, HP 085879956894/02748214896, Jl. Tentara Pelajar No. 14 Yogyakarta disebut sebagai alamat karena dapat memberi petunjuk atau membimbing sampai lokasi usaha.

\subsection{Berkomponen Nama-Spesifikasi- Alamat}

Data iklan yang memiliki tiga slot, yaitu nama, spesifikasi, dan alamat seperti contoh data (3) - (6) berikut ini.

(3)

\section{FALICHA TOUR \& TRAVEL}

Melayani:

Agen Tiket Pesawat \& Kereta Api

Biro Jasa UMROH \& Haji Plus

HOTEL, Paket Wisata

Pulsa HP \& Listrik (PRA Bayar \&

PASCA BAYAR)

Pembayaran Online (BPJS, FIF, BAF, PDAM, dll.)

Cp: Telp/WA:

085750805404

081254428465

(4)

\section{GRIYA MUSTIKA SEDAYU}


HARGA 250jt

grandprize HONDA VARIO 2 unit

call:

082135244411

085729755800

08179447478

(5)

\section{Mini \\ Waterpark}

NOW OPEN

HTM: RP.15.000

Informasi:

02746429660

Jl. Magelang KM 2 (Jl. Jambon)

Sinduadi, Mlati, Kab. Sleman

D.I.Y-Indonesia

(6)

\section{Nabawi Mulia \\ Tour Travel}

17 APRIL 2017 MADINAH

UMROH 11

HARI + TURKI

LANDING

Rp.26,975jt

UMROH

RAMADHAN

25 Mei 2017 BY GARUDA

INDONESIA

$$
\text { Rp.28,975jt }
$$

Jl. Suryodiningratan 3 Yogyakarta 55141

Telp. 0274-381642, 372519

HP/WA : 087839988080 ,

082135331007

Contoh (3)-(6) berupa slot nama, slot spesifikasi, dan slot alamat. Struktur contoh (3) pengisi slot nama tuturan Falicha Tour \&Travel untuk membedakan dengan usaha sejenis yang lain.Struktur pengisi slot spesifikasi terlihat pada penggunaan bentuk tuturan Melayani: agen tiket pesawat \&kereta api, biro jasa umroh \&haji plus hotel, paket wisata pulsa HP\& Listrik (prabayar \&pasca bayar), pembayaran online (BPJS, FIF, BAF, PDAM, dll.)untuk menjelaskan jenis usaha yang ditawarkan. Struktur pengisi slot alamatberupa nomorCP: $\quad$ Telp/WA: 085750805404 , 081254428465 dipergunakan untuk komunikasi.Struktur contoh (4) pengisi slot nama Griya Mustika Sedayu disebut sebagai nama untuk membedakan dengan usaha sejenis yang lain.Struktur pengisi slot spesifikasi terlihat pada penggunaan bentukharga 250jt, grandprize honda vario 2 unituntuk menjelaskan jenis usaha yang ditawarkan. Struktur pengisi slot alamatberupa nomorCP: Telp/WA: call: 082135244411,08572975580008179447 478dipergunakan untuk komunikasi penjual dan pembeli.

Struktur contoh (5) pengisi slot nama atau identitas Mini Waterpark disebut sebagai nama untuk membedakan dengan usaha sejenis yang lain.Struktur pengisi slot spesifikasi terlihat pada penggunaan bentuktuturan now open htm: rp.15.000 untuk menjelaskan jenis usaha yang ditawarkan. Struktur pengisi slot alamat tuturan Jl. Magelang KM 2 (Jl. Jambon), Sinduadi, Mlati, Kab. Sleman, D.I.YIndonesia sebagai alamat memberi petunjuk atau membimbing sampai lokasi usaha. Struktur contoh (6) pengisi slot nama atau identitas (Nabawi Mulia, Tour Travel) disebut sebagai nama untuk membedakan dengan usaha sejenis yang lain.Struktur pengisi slot spesifikasi terlihat pada penggunaan bentuk17 April 2017: Umroh 11 hari + Turki, landing Madinah rp.26,975jt dan 25 mei 2017: umroh ramadhan, by Garuda Indonesia rp.28,975jt untuk menjelaskan jenis usaha yang ditawarkan. Struktur pengisi slot alamat $\mathrm{Jl}$. Suryodiningratan 3 Yogyakarta 55141 sebagai alamat memberi petunjuk atau 
membimbing sampai lokasi usaha. Slot alamat disertakan pula HP/WA: 087839988080, 082135331007 bermanfaat untuk komunikasi perihal pemesanan. Struktur nama, spesifikasi, dan alamat muncul pada biro perjalanan (3) dan (6), jasa jual beli (4), dan tempat rekreasi atau tempat hiburan (5).

\subsection{Berkomponen Nama-Atribusi-Alamat}

Data iklan yang memiliki struktur tiga unsur nama, atribusi dan alamat seperti contoh berikut ini.

(6)

NIELA SARY Resto
PUSAT NASI MERAH Khas
Gunungkidul
\& Oleh-Oleh

Jl. Wonosari-Jogja Km 2,5 Siyono, Playen GK Telp. (0274)

393544/087839597774

www.nielasary.com email:nilasariku_gk@yahoo.-com

(7)

\section{KURSUS BARBERSHOP CUKUR RAMBUT BERGARANSI} www.handercut.com

0877-3835-1841

Contoh data (6) memiliki struktur nama, atribusi, dan alamat. Struktur pengisi slot nama atau identitas dapat dilihat pada penggunaan bentuk Niela Sary. Bentuk Niela Sary disebut sebagai identitas untuk membedakan dengan usaha sejenis yang lain. Bentuk Pusat Nasi Merah \& OlehOleh dan Khas Gunungkidul sebagai atribusi untuk menjelaskan kekhasan layanan. Struktur pengisi slot alamat terlihat pada $\mathrm{Jl}$. Wonosari-Jogja Km 2,5 Siyono, Playen GK, yang dilengkapi nomor telepon dan alamat surel, yaitu www.nielasary.com dan email:nilasariku gk@yahoo.-com. Unsur alamat dapat memberi petunjuk atau membimbing sampai lokasi usaha.

Contoh data (7) pengisi slot nama atau identitas dapat dilihat pada penggunaan bentuk Kursus Barbershop. Bentuk Kursus Barbershop disebut sebagai identitas untuk membedakan dengan usaha sejenis yang lain. Bentuk Cukur Rambut Bergaransi sebagai atribusi untuk menjelaskan kekhasan layanan. Struktur pengisi slot alamat berupa nomor telepon 0877-3835-1841 dan surel www.handercut.com. Contoh (6) pola struktur khas karena spesifikasi dan atribusi digabung. Contoh sejenis iklan pola struktur nama, atribusi, dan alamat seperti berikut ini.

(7)

\section{DAGADUwww.dagadu.co.id DJOKDJA}

\author{
DAGADU \\ BARU. SERU
}

(8)

\section{TOKO \\ POJOK 2}

Sompil

Pilihan Tepat Berbelanja

WONOSARI-JOGJA-KM.5-

LOGANDENG-PLAYEN-GK

Contoh data (7) pengisi slot nama atau identitas dapat dilihat pada penggunaan bentuk Dagadu Djokdja. Bentuk Dagadu Djokdja disebut sebagai nama atau identitas untuk membedakan dengan usaha sejenis yang lain. BentukDagaduBaru Seru sebagai atribusi untuk menjelaskan kekhasan layanan. Struktur pengisi slot alamat berupa surel www.dagadu.com. Contoh data (8) pengisi slot nama atau identitas dapat dilihat pada penggunaan bentukTokoPojok 2 . Bentuk TokoPojok 2disebut sebagai nama atau identitas untuk membedakan dengan usaha sejenis yang lain. BentukSompil, Pilihan Tepat Berbelanja sebagai atribusi untuk menjelaskan kekhasan layanan. Struktur pengisi slot alamat Wonosari-JogjaKm.5-Logandeng-Playen-GK dapat memberi 
petunjuk atau membimbing sampai lokasi usaha.

\subsection{Berkomponen Spesifikasi-Atribusi-}

Alamat

Jenis iklan yang memiliki struktur unsur spesifikasi, atribusi dan alamat tanpa nama ditemukan pada contoh seperti contoh data (9)—(10) berikut ini.

(9)

\section{RUMAH MINIMALIS \\ MEWAH MURAH \\ HANYA 19 JT}

\section{Selamat Hari Raya Idul Fitri}

087739399050

(10)

\section{SPACE IKLAN \\ DISEWAKAN}

BISA MINGGUAN, BULANAN \& TAHUNAN

Hubungi:

0813-2936-9999

Contoh data (9) dan (10) berupa iklan jual beli. Contoh (9) struktur pengisi slot spesifikasi terlihat pada penggunaan bentuk Rumah minimalis mewah murah hanya $19 \mathrm{jt}$ untuk menjelaskan jenis usaha yang ditawarkan. Bentuk Selamat Hari Raya Idul Fitri sebagai atribusi untuk menjelaskan kekhasan layanan. Struktur pengisi slot alamat berupa nomor telepon 087739399 050 untuk komunikasi antara penjual dan pembeli. Contoh data (10) struktur pengisi slot spesifikasi terlihat pada penggunaan bentuk Space Iklan Disewakan untuk menjelaskan jenis usaha yang ditawarkan. Bentuk Bisa Mingguan, Bulanan \& Tahunan sebagai atribusi untuk menjelaskan kekhasan layanan. Struktur pengisi slot alamat berupa informasi Hubungi: 08132936-9999 untuk komunikasi antar pembeli dan penjual. Contoh iklan sejenis struktur spesifikasi, alamat, dan atribusi seperti contoh berikut.

(11)

UMROH RAMADHAN

25 Mei 2017

BY GARUDA

INDONESIA

$$
\text { Rp.28,975jt }
$$

HP/WA: 087839988080, 082135331007

Meraih Kekhusukan Ibadah dengan Pelayanan Terbaik.

\subsection{BerkomponenSpesifikasi-Nama- Atribusi}

Jenis iklan yang memiliki struktur unsur spesifikasi, nama, dan atribusi tanpa nama ditemukan pada contoh data seperti berikut.

(12)

\section{ES DAWET \\ IRENG \\ "IRCISA" \\ $100 \%$ \\ GULA ASLI \\ ENAK NIKMAT SEGERRRR!!! \\ MURAAHHHH...}

Contoh (12) struktur pengisi slot spesifikasi terlihat pada penggunaan bentuk Es Dawet Ireng sebagai spesifikasi untuk menjelaskan jenis usaha yang ditawarkan. Unsur nama dapat dilihat pada penggunaan bentuk "Ircisa". Bentuk tuturan "Ircisa" sebagai nama untuk membedakan dengan usaha sejenis yang lain. Struktur atribusi 100 \%gula asli, enak nikmat segerrrr!!!, muraahhhh....untuk menjelaskan kekhasan layanan.

\subsection{Berkomponen Nama-Spesifikasi}

Jenis iklan yang memiliki struktur nama dan spesifikasi seperti contoh berikut ini. 
(13)

Ungu

\section{Baby Shop \& Spa \\ PUSAT PERLENGKAPAN BAYI, IBU, DAN ANAK}

(14)

\section{VIVO \\ Smart Phone}

20MP

\section{SOFTLIGHT CAMERA PERFECT SELFIE}

Contoh data (13) struktur pengisi slot nama dapat dilihat pada penggunaan bentuk Ungu. Bentuk Ungu sebagai nama untuk membedakan dengan usaha sejenis yang lain. Struktur pengisi slot spesifikasi terlihat pada penggunaan bentuk BabyShop \&Spa, Pusat Perlengkapan Bayi, Ibu, dan Anakuntuk menjelaskan jenis usaha yang ditawarkan.Contoh (14) struktur pengisi slot nama dapat dilihat pada penggunaan bentuk Vivo Smart Phone. Bentuk Vivo Smart Phone sebagai nama untuk membedakan dengan usaha sejenis yang lain. Struktur pengisi slot spesifikasi terlihat pada penggunaan bentuk 20mp, softlight camera, perfect selfie untuk menjelaskan jenis usaha yang ditawarkan. Jenis iklan berstruktur nama dan spesifikasi muncul dalam iklan jual beli.

Data iklan setipeyang memiliki dua unsur, yaitu spesifikasi dan nama seperti contoh berikut ini.

\section{JOGLO}

Wisata Kuliner

$$
\text { RUMAH MAKAN }
$$

Contoh (15) struktur pengisi slot spesifikasi terlihat pada penggunaan bentuk Wisata Kuliner untuk menjelaskan jenis usaha yang ditawarkan. Struktur pengisi slot nama dapat dilihat pada penggunaan bentuk Rumah Makan Joglo. Bentuk Rumah
Makan Joglo sebagai nama untuk membedakan dengan usaha sejenis yang lain.

\subsection{Berkomponen Nama-Alamat}

Data iklan yang memiliki dua unsur berupa spesifikasi dan alamat seperti contoh berikut ini.

$$
\begin{array}{lr}
\text { AD } & \\
\text { SPACECall } & 0274-560269 \\
& 08122559650
\end{array}
$$

\section{ANTON PHOTO}

TELP: 08122721440

email:

antonphoto studio@yahoo.com

JL. GODEAN KM. 14,7 (TIMUR

PASAR NGIJON)

(18)

\section{Universitas \\ Cokroaminoto \\ Yogyakarta}

Kampus:

Jl. Perintis Kemerdekaan, Gambiran,

Umbulharjo, Yogyakarta 55161

email:

info@ucy.ac.id.http://www.ucy.ac.id,

Telp. (0274) 372274 (Hunting)-Fax.

(0274) 4340644

Contoh data (16) pengisi slot nama atau identitas dapat dilihat pada penggunaan bentukAD SPACE. Bentuk AD SPACE sebagai nama atau identitas untuk membedakan dengan usaha sejenis yang lain. Struktur pengisi slot alamat berupa nomor telepon Call 0274-560269, 08122559650 dapat memberi informasi sampai lokasi usaha. Contoh (17) pengisi slot nama atau identitas dapat dilihat pada penggunaan bentuk Anton Photo. Bentuk Anton Photo sebagai nama atau identitas untuk membedakan dengan usaha sejenis yang lain. Struktur pengisi slot alamat Telp: 08122721440,

Email: antonphoto_studio@yahoo.com,.Jl. Godean 
Km. 14,7 (Timur pasar Ngijon)memberi petunjuk atau informasi sampai lokasi usaha. Contoh (18) pengisi slot nama atau identitas dapat dilihat pada penggunaan bentuk Universitas Cokroaminoto Yogyakarta. Bentuk Universitas Cokroaminoto Yogyakarta sebagai nama atau identitas untuk membedakan dengan usaha sejenis yang lain. Struktur pengisi slot alamat Jl. Perintis Kemerdekaan, Gambiran, Umbulharjo, Yogyakarta 55161, email: info@ucy.ac.id.http://www.ucy.ac.id, Telp. (0274) 372274 (Hunting)-Fax. (0274) 4340644memberi petunjuk atau informasi sampai lokasi usaha. Iklan berstruktur nama dan alamat contoh (16) - (18) muncul pada iklan jenis persewaan, usaha jasa, dan lembaga pendidikan. Contoh iklan setipe berstruktur nama dan alamat seperti contoh (19) - (21) berikut ini.

(19)

$$
\begin{array}{ll}
\text { Andi's } & 0274 \\
& 566246 \\
& 557459
\end{array}
$$

Jl. Gowongan Kidul No. 151, Yogyakarta

(20)

ROS-IN HOTEL

YOGYAKARTA

Telp. (0274)384543 $\mathrm{Jl}$.

Lingkar Selatan No. 110, Yogyakarta www.rosinhoteljogja.com

(21)

\section{KSPP SYARIAH \\ BMT UMMAT \\ CABANG PLAYEN}

(logo telepon) (0274) 2910412

\subsection{BerkomponenSpesifikasi-Atribusi}

Data iklan yang memiliki dua unsur berupa spesifikasi dan atribusi seperti contoh data (22) - (23) berikut ini.

\section{SERVICE \\ HP}

Hardware

Software

Bisa ditunggu

Cek kerusakan...GRATIS

BERGARANSI

(23)

KREDIT HP

PROSES $\pm 30_{\text {MENIT }}$

HARGA KREDIT/CASH

S A M A

\subsection{Berkomponen Spesifikasi-Alamat}

Data iklan yang memiliki dua unsur berupa spesifikasi dan alamat seperti contoh (24) - (29) berikut ini.

\section{SEWA MOBIL \\ $100 \mathrm{Rb}$}

Calya - Sigra - Avanza - Xenia

Bus Besar Pariwisata Seat 50-40-30

AC/Non AC (700rb/day)

082135022539

J1. Ringroad Selatan No. 57

Yogyakarta

\section{RUMAH DIJUAL}

RUMAH SUBSIDI

Lokasi Krembangan

Kulon Progo

0816685096

087838541666

(26) 
Rp.6000;

JL. JOGJA-WATES KM. 16, SENTOLO, KULONPROGO

(27)

\section{Space \\ for Rent}

Call

0811269485

0817531440

\section{SPACE \\ IKLAN \\ DISEWAKAN}

\section{5}

Contoh (24) struktur pengisi slot spesifikasi terlihat pada penggunaan bentuk Sewa mobil 100 rb, Calya-Sigra-AvanzaXenia, Bus Besar Pariwisata Seat 50-40-30 AC/Non AC (700rb/day) untuk menjelaskan jenis usaha yang ditawarkan. Struktur pengisi slot alamat $\mathrm{Jl}$. Ringroad Selatan No. 57 Yogyakarta sebagai petunjuk sampai lokasi usaha dan dicantumkan pula nomor Telepon 082135022539. Contoh (25) struktur pengisi slot spesifikasi terlihat pada penggunaan bentuk Rumah dijual, rumah subsidi, Lokasi Krembangan, Kulon Progo untuk menjelaskan jenis usaha yang ditawarkan. Struktur pengisi slot alamat $J l$. Ringroad Selatan No. 57 Yogyakarta sebagai petunjuk sampai lokasi usaha dan dicantumkan pula nomor telepon 082135022539.

Contoh (26) struktur pengisi slot spesifikasi terlihat pada penggunaan bentuk Nasi pecel sayur \& tumpang Rp.6000 untuk menjelaskan jenis usaha yang ditawarkan. Struktur pengisi slot alamat $\mathrm{Jl}$. Jogja-Wates Km. 16, Sentolo, Kulonprogo sebagai petunjuk sampai lokasi usaha. Contoh (27) struktur pengisi slot spesifikasi terlihat pada penggunaan bentuk Jual kain kiloan, Banyu Urip, Margoagung, Seyegan, Sleman untuk menjelaskan jenis usaha yang ditawarkan. Struktur pengisi slot alamat dicantumkan nomor telepon 081804189216 sebagai sarana komunikasi sampai lokasi usaha.

Contoh (28) struktur pengisi slot spesifikasi terlihat pada penggunaan bentuk Space for Rent untuk menjelaskan jenis usaha yang ditawarkan. Struktur pengisi slot alamat dicantumkan nomor telepon 0811269485, 0817531440 sebagai sarana komunikasi sampai lokasi usaha. Contoh (29) struktur pengisi slot spesifikasi terlihat pada penggunaan bentuk Space Iklan Disewakan untuk menjelaskan jenis usaha yang ditawarkan. Struktur pengisi slot alamat dicantumkan nomor telepon 08121557225 sebagai sarana komunikasi sampai lokasi usaha. Iklan berstruktur spesifikasi dan alamat contoh (33)-(38) muncul pada iklan jenis persewaan contoh (24) dan (28), (29), jual beli contoh (25) dan (27), dan contoh (26) usaha jasa boga.

\subsection{Berkomponen Atribusi-Nama}

Data iklan yang memiliki dua unsur atribusi dan nama seperti contoh data(30) (31) berikut ini.

G4plus untuk semua

WARUNG BUKIT BINTANG

JELAS 


\section{KACAMATANYA \\ MURAH \\ HARGANYA \\ MANDING}

Contoh data (30) berupa iklan berstruktur atribusi dan nama. Bentuk Gplus untuk seтиa sebagai atribusi untuk menjelaskan kekhasan layanan. Struktur pengisi slot nama dapat dilihat pada penggunaan bentuk Warung Bukit Bintang. Bentuk WarungBukit Bintang sebagai nama untuk membedakan dengan usaha sejenis yang lain. Contok (31) bentuk tuturan jelas kacamatanya murah harganya sebagai atribusi untuk menjelaskan kekhasan layanan. Struktur pengisi slot nama dapat dilihat pada penggunaan bentuk Manding. Bentuk Manding sebagai nama untuk membedakan dengan usaha sejenis yang lain.

\subsection{Berkomponen Nama}

Data iklan yang memiliki struktur nama seperti contoh berikut ini.

\section{Angkringan \\ "SEHAT" \\ Mbak Yul}

Struktur pengisi slot nama contoh (32) dapat dilihat pada penggunaan bentuk Angkringan Sehat Mbak Yul. Bentuk Angkringan Sehat Mbak Yul sebagai nama untuk membedakan dengan usaha sejenis yang lain. Jenis iklan berstruktur nama muncul dalam jenis jual beli.

\subsection{Berkomponen Spesifikasi}

Data iklan yang memiliki struktur nama seperti contoh berikut ini.

\section{(33) HP}

$$
\begin{gathered}
\text { ANDROID } 4 \mathrm{G} \\
\text { FREE } \\
\text { 65 }_{\mathrm{GB}}
\end{gathered}
$$

\section{Hanya 600 RIBUAN}

Contoh (33) struktur pengisi slot spesifikasi terlihat pada penggunaan bentukHp Android 4 G Free 65 GB Hanya 600 Ribuan untuk menjelaskan jenis usaha yang ditawarkan. Struktur spesifikasi muncul pada jenis iklan jual beli.

\subsection{Berkomponen Atribusi}

Data iklan yang memiliki satu unsur berupa atribusi seperti contoh berikut ini.

$$
\begin{aligned}
& \text { BAYARLAH PAJAK BUMI \& } \\
& \text { BANGUNAN (PBB) ANDA TEPAT } \\
& \text { PADA WAKTUNYA }
\end{aligned}
$$

\section{PATUHILAH RAMBU-RAMBU LALULINTAS}

Agar Selamat Sampai Tujuan

\section{Pilih Mutu... Pilih Mutiara}

Contoh data (34) - (36) berupa iklan berstruktur slot atribusi. Contoh tuturan Bayarlah Pajak Bumi \& Bangunan (PBB) Anda tepat pada waktunya data (34) dantuturan Patuhilah Rambu-Rambu Lalulintas, Agar Selamat Sampai Tujuan data (35) berupa slogan layanan masyarakat. Contoh (36) tuturan Pilih Mutu... Pilih Mutiara sebagai atribusi untuk menjelaskan kekhasan layanan.

\section{PENUTUP}

Data menunjukkan bahwa penggunaan bahasa pada iklan media luar ruang terkait struktur wacana ditemukan tiga belas struktur slot, yaitu slot nama, slot spesifikasi, slot atribusi, dan slot alamat. Ketiga belas struktur slot seperti berikut.
(1) Berkomponen
nama-spesifikasi- atribusi-alamat
(2) Berkomponen nama-spesifikasi-alamat
(3) Berkomponen nama-atribusi-alamat 
(4) Berkomponen spesifikasi-atribusialamat

(5) Berkomponen spesifikasi-nama-atribusi

(6) Berkomponen nama-spesifikasi

(7) Berkomponen nama-alamat

(8) Berkomponen spesifikasi-atribusi

(9) Berkomponen spesifikasi-alamat

(10) Berkomponen atribusi-nama

(11) Berkomponen nama

(12) Berkomponen spesifikasi

(13) Berkomponen atribusi

\section{DAFTAR PUSTAKA}

Arifin, E, Zaenal, dkk. 1992. Pemakaian Bahasa dalan Iklan Berita dan Papan Reklame. Jakarta: Pusat Pembinaan dan Pengembangan Bahasa, Departemen Pendidikan dan Kebudayaan.

Baryadi, I. Praptomo. 2002. Dasar-Dasar Analisis Wacana dalam Ilmu Bahasa. Jogjakarta: Pustaka Gondho Suli.

Departemen Pendidikan Nasional. 2008. Kamus Besar Bahasa Indonesia. Jakarta: Gramedia.

Indiyastini, Titik. 2014. Kajian Wacana Iklan Baris Tentang Properti di Media Massa Cetak dalam Prosiding Diskusi Ilmiah (Lokakarya Hasil Penelitian Kebahasaan dan Kesastraan) Balai Bahasa Provinsi DIY, 29 September-1 Oktober 2014.
Jaiz, Muhammad. 2014. Dasar-Dasar Periklanan. Yogyakarta: Graha Ilmu.

Riani, dkk. 2016. Penggunaan Bahasa Indonesia pada Media Luar Ruang di Daerah Istimewa Yogyakarta. Yogyakarta: Balai Bahasa DIY.

Setiyanto, Edi, 2012. "Wacana Hortatori Ular-Ular Bahasa Jawa: Kajian Slot dan Struktur Slot”. Dalam Widyaparwa, Volume 40, Nomor 1, Juni 2012, hlm.13-24.

------. 2014. Wacana Iklan Susu Balita: Kajian Analisis Wacana Kritis dalam Prosiding Diskusi Ilmiah (Lokakarya Hasil Penelitian Kebahasaan danKesastraan) Balai Bahasa Provinsi DIY, 29 September-1 Oktober 2014.

------. 2016. Bahasa Jawa dalam Usaha Jasa Boga di Kota Yogyakarta dalam Prosiding Kongres Bahasa Jawa VI, tanggal 8-12 November 2016 di Hotel Inna Garuda Yogyakarta.

Sudaryanto. 2015. Metode dan Aneka Teknik Analisa Bahasa: Pengantar Penelitian Wahana Kebudayaan secara Linguistik. Yogyakarta: Sanata Dharma University Press.

Tim Penyusun. 2016. Pedoman Pemantauan Penggunaan Bahasa di Media Luar Ruang. Jakarta: Badan Pengembangan dan Pembinaan Bahasa, Kementerian Pendidikan dan Kebudayaan. 